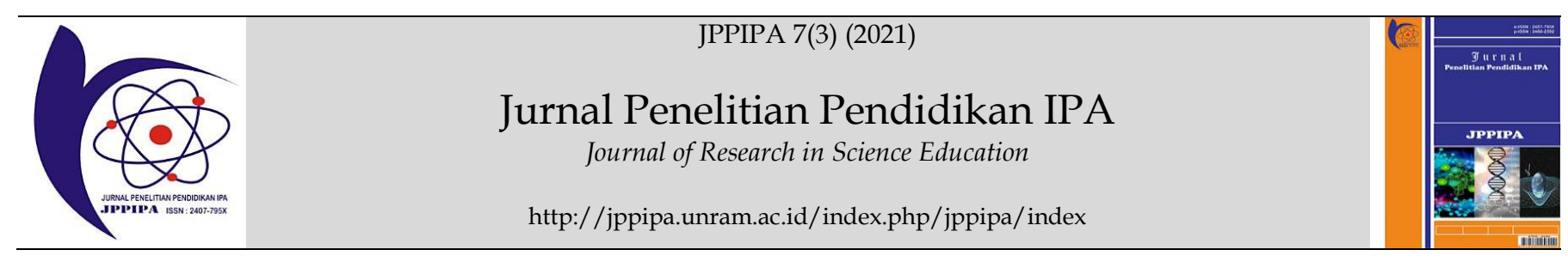

\title{
Students and the Sea: Ocean Literacy in Tanjungpinang, Indonesia
}

\author{
Nur Eka Kusuma Hindrasti ${ }^{1}$ \\ ${ }^{1}$ Biology Education Department, Universitas of Maritim Raja Ali Haji, Tanjungpinang, Indonesia
}

DOI: $\underline{10.29303 / \text { ippipa.v7i3.725 }}$

\section{Article Info}

Received: April 28,h, 2021

Revised: July $8^{\text {th }}, 2021$

Accepted: July 13th, 2021

\begin{abstract}
Low levels of 'ocean literacy' has been identified in many countries and can be a barrier for citizens to engage in environmentally responsible behavior even though improving public awareness about the ocean can benefit society and the environment. This study assessed the level of knowledge, attitude, and behavior towards the ocean of students grades 10-11 (ages 15-17) in Tanjungpinang, Indonesia, a region with strong connections with the sea. A survey was used in a public school and a private school, with a total of 200 students participating in a test about ocean knowledge and a survey about ocean attitude and behavior. Many test questions were aligned with the SOLE (The Survey of Ocean Literacy and Experience) based on 'Ocean Literacy Principles' established by the Ocean Literacy Campaign in the United States. Overall, respondents possess a moderate level of knowledge, a highly positive attitude towards the ocean environment, and a moderate level category on behavior. There are significant differences: the level of behavior in terms of class level, the level of knowledge, and attitudes in terms of subject interest. There is no significant difference in knowledge between private and public schools. There is a correlation between attitude and knowledge and also between attitude and behavior.
\end{abstract}

Keywords: ocean literacy; students; Tanjungpinang

Citation: Hindrasti, N. (2021). Students and the Sea: Ocean Literacy in Tanjungpinang, Indonesia. Jurnal Penelitian Pendidikan IPA, 7(3), 452-457. doi:https:// doi.org/10.29303/jppipa.v7i3.725

\section{Introduction}

Citizens in many countries have a poor understanding of ocean issues and marine science (Boubonari et al., 2013; Chen \& Tsai, 2015; Eddy, 2014; Fletcher \& Potts, 2007; Pearson et al., 2014; Umuhire \& Fang, 2015), which can be a barrier for citizens to engage in environmentally responsible behavior (Chen \& Tsai, 2015; Fletcher \& Potts, 2007). Public awareness about the ocean can benefit society and the environment. The sea covers $71 \%$ of the earth's surface and is the dominant feature of the earth. The ocean regulates the weather and climate, supplies nearly all of the Earth's oxygen, supports a large diversity of life and provides a rich source of food for human populations (Cava et al., 2005). Given that the ocean is the dominant feature of the planet and is strongly related to other terrestrial systems of science (Hoffman \& Barstow, 2007), Science Literacy or Environment Literacy cannot be achieved without Ocean Literacy (Payne \& Zimmerman, 2010). This can be exemplified as follows: cannot effectively understand the climate system without understanding the role of the oceans in climate and cycle variability, productivity without photosynthesis and ocean chemosynthesis, and biodiversity without marine ecosystems. Thus, understanding the ocean is integral to understanding planets.

Understanding the ocean is important to understand and conserve the ocean and protect the planet we live in (Cava et al., 2005). Cava et al. (2005) defined OL as "the influence of the sea on you and your influence on the sea" and identified seven principles of OL and the basic concepts of OL. Someone who has OL must have three aspects: content knowledge about the sea, a good attitude towards the marine environment, not violating marine values, and behaving well towards the marine environment (Strang \& Schoedinger, 2007). 
In line with Yeung's (1998) opinion, these three aspects are also important for environmental sustainability, however Yeung gives a different term instead of OL, namely environmental awareness (Yeung, 1998).

Berkemeyer (2012) argues that there is a relationship between environmental education, public awareness, and sustainable development. To achieve a marine literate society, marine science must be integrated into educational practices, research, curriculum, textbooks, and assessments (Tran et al., 2010). Teachers play a key role in future generations of environmental literacy (World Commission on Environment and Development, 1987) and are more likely to produce environmentally literate students when they themselves have good knowledge, attitudes, and concern for the environment, demonstrated by their behavior (Tuncer et al., 2009). Hence, the plausible assumption that successful OL integration in schools requires the commitment of teachers to have a good knowledge of OL principles and a positive attitude towards the ocean. However, it is questionable whether teachers are seaworthy and ready to tackle this challenge and to what extent teacher education programs prepare teacher candidates for it (Boubonari et al., 2013).

So far, marine education has received less attention from the Indonesian government. However, LIPI, through the Education Component of the Coral Reef Rehabilitation and Management Program-Coral Triangle Initiative (COREMAP-CTI), has been active in providing input related to material and material for competency insights of chemistry to Puskurbuk. This further strengthens the possibility of implementing marine education in Indonesia, plus a serious response from the Minister of Education and Culture at the meeting in the discussion of cooperation between the Coordinating Ministry for Maritime Affairs and the Ministry of Education and Culture. The principal of the cooperation includes the development, implementation, and evaluation of the maritime content education curriculum, which is carried out at all lines, levels, and types of education as a forum and/or means of developing changes in knowledge, insights, values, concerns, attitudes, and behaviors that support maritime development. The maritime curriculum is implemented as an effort to support the aspiration of the country, Indonesia, as the world's maritime axis, which was emphasized by President Jokowi in his speech at the 9th East Asia Summit (EAS) Summit on 13 November 2014 in Nay Pyi Taw, Myanmar. Rebuilding Indonesia's maritime culture as the first pillar does not mean abandoning the concept of land, but it should go hand in hand. There are so many sea potentials that the state has not noticed, even though the country claims to be a maritime state for centuries. As a result, people have less awareness of the marine environment.

The study investigates the level of three aspects of ocean literacy (knowledge, attitude, and behavior towards ocean) held by Tanjungpinang private and public school students grade 10-11 (age 15-17), the value they place on the marine environment. The research questions were (1) to measure the level of student's ocean literacy, (2) to determine if there significant differences of the three aspects of ocean literacy in terms of grade level and subject interest, (3) to determine is there a significant difference of the three aspects of ocean literacy between the private and public schools, (4) is there is a correlation between the three aspects of ocean literacy. The study aims to inform educators and provide insight into the level of ocean knowledge, attitudes, and behavior of Tanjungpinang students.

\section{Method}

A survey was used to address the research objectives. The instrument in this study was an assessment instrument of ocean literacy for grades 1011 (ages 15-17) developed by researchers (Hindrasti, 2018a). The instruments were a test for measuring the ocean kbowledge and a questionnaire to measure the ocean attitude and behavior. In order to ascertain their knowledge concerning the ocean and coastal issues, the 15 (fifteen) questions were designed following SOLE (The Survey of Ocean Literacy and Experience) (Markos et al., 2015). SOLE was designed based on 'The Seven Essential Principles and 45 Fundamental Concepts of Ocean Literacy' created in the U.S. by marine education experts (COSEE (Centers for Ocean Sciences Education Excellence). Ocean literacy: the essential principles and fundamental concepts for learners of all ages. (National Oceanic and Atmospheric Administration, 2006). The Seven Essential Principles of Ocean Literacy are ocean, ocean, and life shape earth, weather and climate, habitability, biodiversity, human connections, and ocean largely unexplored. The first questionnaire consists of 20 items that measured the respondent's attitudes toward the marine environment and were designed following the method used in Chen and Tsai (Chen \& Tsai, 2015) based on The NEP (New Environment Paradigm) (Dunlap, 2008). The aspects of the first questionnaire are eco-crisis, limit to growth, anti-anthropocentrism, the balance of nature, and antiexemptionalism. The second questionnaire consists of 14 items that measured respondents' behavior toward the marine environment were designed following the method used in Chen and Tsai (Chen \& Tsai, 2015) based on aspects of peoples' environmental actions by Hungerford (Hungerford \& Volk, 1990). The aspects are 
persuasion, consumer action, eco-management, political action, and legal action.

Senior high school students were the target population in this study. The samples were 100 public school students and 100 private school students. The research sample is hereinafter referred to as the respondent. In August 2018, researchers went to schools and gave printed tests and questionnaires to respondents. All respondents filled in and returned the tests and questionnaires. Furthermore, a face-to-face survey was conducted in September 2018 to clarify respondents' answers and also the teachers.

The data used were the students' knowledge, attitudes, and behavior as indicated by the scores obtained when filling out the test instruments and questionnaires. The score obtained is made a percentage. Every three aspects of ocean literacy are determined based on the average of all respondents with the five criteria shown in Table 1.

Table 1. The Criteria of 3 Ocean Literacy Aspects

\begin{tabular}{lll}
\hline No. & Score Percentage (\%) & The Criteria \\
\hline 1 & $81-100$ & Very high \\
2 & $61-80$ & High \\
3 & $41-60$ & Moderate \\
4 & $21-40$ & Low \\
5 & $0-20$ & Very low \\
\hline
\end{tabular}

Descriptive statistic was used to measure the level of student's ocean literacy. Mann Whitney U or Independent T-test was used to determining their significant differences in the three aspects of ocean literacy in terms of grade level and subject interest. Mann Whitney $U$ was used to determine the significant difference between the three aspects of ocean literacy between private and public schools. To assess the correlation between ocean knowledge, attitudes and behavior, Spearman Correlation was employed. All data analyses were performed using the SPSS program, and a p-value of 0.05 was used to check if the difference in means or the correlation between variables is statistically significant. The research designs are shown in Figures 1, 2, and 3.

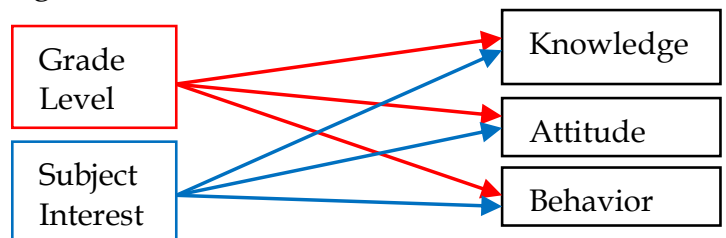

Figure 1. Research design of different tests of the three aspects of ocean literacy in terms of grade level and subject interest.

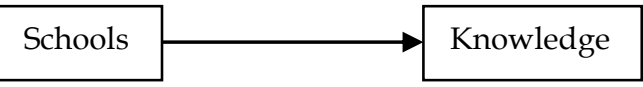

Figure 2. Research Design of Different Tests of The Ocean Knowledge Between Private and Public Schools

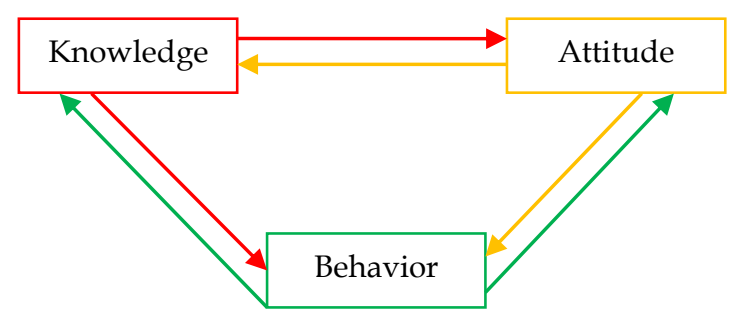

Figure 3. Research Design of The Correlation Test Of The Three Aspects of Ocean Literacy

\section{Result and Discussion}

The results of the study answered the stated research objectives, shown in Tables 2,3,4, and 5 .

Table 2. The level of student's ocean literacy

\begin{tabular}{llll}
\hline & \multicolumn{3}{l}{ The aspect of Ocean Literacy } \\
\cline { 2 - 4 } & Knowledge & Attitude & Behavior \\
\hline Mean & 47.13 & 75.60 & 51.50 \\
Criteria & Moderate & High & Moderate \\
\hline
\end{tabular}

Table 3. The Results of Different Tests of The Three Aspects of Ocean Literacy In Terms of Grade Level And Subject Interest.

\begin{tabular}{|c|c|c|c|c|c|}
\hline \multirow[t]{2}{*}{ No } & \multicolumn{2}{|l|}{ Variable } & \multirow{2}{*}{$\begin{array}{l}\text { The difference in } \\
\text { average score }\end{array}$} & \multirow{2}{*}{ P-Value } & \multirow[b]{2}{*}{ Conclusion } \\
\hline & Independent & Dependent & & & \\
\hline \multirow[t]{3}{*}{1} & Grade level & Knowledge & 5.42 & 0.504 & Not Significant \\
\hline & & Attitude & 2.77 & 0.735 & Not Significant \\
\hline & & Behavior & 4.48 & 0.003 & Significant \\
\hline \multirow[t]{3}{*}{2} & Subject interest & Knowledge & 36.08 & 0.000 & Significant \\
\hline & & Attitude & 28.89 & 0.000 & Significant \\
\hline & & Behavior & 1.91 & 0.209 & Not Significant \\
\hline
\end{tabular}

Table 4. The Results of Different Tests of The Ocean Knowledge Between Private and Public Schools

\begin{tabular}{llllll}
\hline No & $\begin{array}{l}\text { Variable } \\
\text { Independent }\end{array}$ & Dependent & $\begin{array}{l}\text { The difference in } \\
\text { average score }\end{array}$ & P-Value & Conclusion \\
\hline 1 & Schools & knowledge & 11.14 & 0.169 & Not Significant \\
\hline
\end{tabular}


Table 5. The Results of The Correlation Test Of The Three Aspects of Ocean Literacy

\begin{tabular}{llllll}
\hline \multirow{2}{*}{ No } & Variable & & \multirow{2}{*}{ P-Value } & Conclusion \\
\cline { 2 - 5 } & Independent & Dependent & & 0.428 & Not Significant \\
2 & Behavior & Knowledge & 0.056 & 0.002 & Significant \\
3 & Attitude & Knowledge & 0.220 & Significant \\
\hline
\end{tabular}

Based on Table 2 showed that ocean literacy of students is a moderate level category on knowledge, high-level category on attitude, and moderate level category on behavior. Students were asked to assess their knowledge of marine and coastal issues. The average score for all 15 questions was 47.13 , indicating that respondents generally had a moderate level of ocean knowledge. The same results were obtained by previous studies (Boubonari et al., 2013; Chen \& Tsai, 2015; Fletcher et al., 2009). The results of the highest student scores were on the 5th principle, namely biodiversity, and the 6th principle, namely human connections. Based on the interview, it was found that students like to discuss especially marine animals. Students in Nova Scotia, Canada, showed the greatest interest in the ocean when it came to marine animals (Guest et al., 2015). Marine knowledge can be enhanced by contextual learning, for example, field trips. Fieldtrip cooperative learning can also improve student cognitive outcomes regarding marine ecology and issues concerning conservation (Sattler \& Bogner, 2016).

The average score for all 20 questions on a questionnaire of students' ocean attitudes was 75.60, indicating that respondents generally had a strong and positive attitude towards the ocean. The students agree that preserving the marine environment for the future is important. Students have a very good attitude on the anti-exemptionalism aspect, especially related to replanting the coastal environment because students are active in mangrove planting activities in coastal areas. The replanting activities are not accompanied by follow-ups such as mangrove care and community education related to mangrove conservation. Students in Taiwan also showed the same results. The positive attitude towards the environment indicates that 'widespread greening' has occurred among university students. However, they are likely to be passive supporters of environmental campaigns or activities (Chen \& Tsai, 2015).

The average score for all 20 questions on the students' ocean behavior questionnaire was 51.50, indicating that respondents generally had a moderate level of behavior towards the ocean. The students are not actively engaged in environmental protection endeavors, particularly in persuasion towards preserving the marine environment, buying protected fish, and reporting environmental policy violations. Namely, they are informed but not much engaged in marine environmental protection. Unlike students in Taiwan, their ocean action is moderate in activities, particularly those involving spending personal incomes and taking legal or political action(Chen \& Tsai, 2015). There are no extracurricular activities related to the preservation of the marine environment in Tanjungpinang, even though the extracurricular activities can be a means for students to be more active in taking action to preserve the marine environment. Informal learning environments (e.g., aquariums, museums, science centers) provide learners with direct access to objects, organisms, and phenomena (Hindrasti, 2018b). The gap between attitudes and action is one that has also been identified in previous research (e.g.(Boubonari et al., 2013; Chen \& Tsai, 2015; Fien et al., 2002; Kollmuss \& Agyeman, 2010)). So that this does not become a gap, it is necessary to pay special attention to the active behavior of the marine environment.

Based on Table 3 showed that there were significant differences: the level of ocean behavior in terms of grade level, the level of ocean knowledge, and attitudes in terms of subject interest. The scores of grades 11 students on the behavior aspect are averagely higher than grade 10, with a difference of 4.48 , except for questions related to consumption measures and efforts to reduce marine waste. Based on interviews with teachers, it was found that students in grade 10 tend to have more obedient behavior than students in grade 11 because they still carry the characteristics of junior high school level students. The scores of Science students on ocean knowledge and attitude aspect are on average higher than class Social. Science students have higher ocean knowledge than social students. This is in line with Hindrasti's research (2018) that ocean literacy is closer to nature than social science(Hindrasti, 2018b).

Based on Table 4 showed that there was no difference in student ocean knowledge between the public and private schools studied. The two schools are both located near the sea. It is not surprising that the results show this. Students at these two schools do not get special lessons related to marine sustainability, even though the schools are located in an archipelagic region. Even though the existence of marine lessons will have an impact on good ocean literacy, as happened in Canada (Guest et al., 2015). The effort to include marine biology materials or subjects in schools 
is not intended for students to have an interest in majoring in Marine Biology or one of the majors at the Faculty of Marine Affairs, but it is hoped that it will be able to stimulate better decisions and policies in the future. A new generation of decision-makers will be able to better value careers related to the ocean and give proper consideration to marine biology as a profession (Lucrezi et al., 2017).

Based on Table 5 showed that there was a correlation between attitude and knowledge and also between attitude and behavior. The pattern of correlations found between knowledge, attitudes, and behavior toward the ocean is generally consistent with observations in past studies concerning environmental literacy (Boubonari et al., 2013; DeWaters \& Powers, 2011; Hsu \& Roth, 1998; Pe'er et al., 2007). Knowledge of the ocean is more strongly associated with attitudinal than behavioral components, but the causal direction of this association should be the focus of future research. In addition, it was found that better attitudes toward the ocean are associated with more positive behavior. However, environmentally supportive attitudes are not always translated into behavior (Yaveltz et al., 2009).

\section{Conclusion}

Tanjungpinang students possess a moderate level of knowledge, a highly positive attitude towards the ocean environment, and a moderate level category on behavior. There are significant differences: the level of behavior in terms of class level, the level of knowledge, and attitudes in terms of subject interest. There is no significant difference in knowledge between private and public schools. There is a correlation between attitude and knowledge and also between attitude and behavior. This study addresses the gap between widespread ocean concerns and low engagement in environmental actions by proposing a multimodal approach: improving marine knowledge and experience in marine-related activities, creating safe recreational spaces at seasides, and reinforcing legal education. These findings recommend that teachers, especially in archipelagic regions, promote ocean literacy in the curriculum to improve ocean literacy in knowledge, attitude, and behavior. This study concludes by highlighting the importance of ocean literacy in the development of ocean citizenship as well as the sustainability of the marine environment.

\section{References}

Boubonari, T., Markos, A., \& Kevrekidis, T. (2013). The Journal of Environmental Education Greek PreService Teachers' Knowledge, Attitudes, and
Environmental Behavior Toward Marine Pollution Greek Pre-Service Teachers' Knowledge, Attitudes, and Environmental Behavior Toward Marine Pollution. The Journal of Environmental Education, 44(4), 232-251. https://doi.org/10.1080/00958964.2013.785381

Cava, F., Schoedinger, S., Strang, C., \& Tuddenham, P. (2005). Science Content and Standards for Ocean Literacy: A Report on Ocean Literacy. In National Geographic (Issue November). http://www.coseeca.net/publications/OLit0405FinalReport.pdf

Chen, C., \& Tsai, C. (2015). Marine environmental awareness among university students in Taiwan: a potential signal for the sustainability of the oceans. Environmental Education Research, June 2015,

$1-20$. https://doi.org/10.1080/13504622.2015.1054266

DeWaters, J. E., \& Powers, S. E. (2011). Energy literacy of secondary students in New York State (USA): A measure of knowledge, affect, and behavior. Energy Policy, 39(3), 1699-1710. https://doi.org/10.1016/j.enpol.2010.12.049

Dunlap, R. (2008). The new environmental paradigm scale: From marginality to worldwide use. Journal of Environmental Education, 40(1), 3-18. https://doi.org/10.3200/JOEE.40.1.3-18

Eddy, T. D. (2014). One hundred-fold difference between perceived and actual levels of marine protection in New Zealand. Marine Policy, 46, 6167. https://doi.org/10.1016/j.marpol.2014.01.004

Fien, J., Poh Ai, I. T.-C., Yencken, D., Sykes, H., \& Treagust, D. (2002). Costs of secondary parasitism in the facultative hyperparasitoid Pachycrepoideus dubius: Does host size matter? The Environmentalist, 22, 205-216. https://doi.org/10.1023/A

Fletcher, S., \& Potts, J. (2007). Ocean citizenship: An emergent geographical concept. Coastal Management, 35(4), 511-524. https://doi.org/10.1080/08920750701525818

Fletcher, S., Potts, J. S., Heeps, C., \& Pike, K. (2009). Public awareness of marine environmental issues in the UK. Marine Policy, 33(2), 370-375. https://doi.org/10.1016/j.marpol.2008.08.004

Guest, H., Lotze, H. K., \& Wallace, D. (2015). Youth and the sea: Ocean literacy in Nova Scotia, Canada. Marine Policy, 58, 98-107. https://doi.org/10.1016/j.marpol.2015.04.007

Hindrasti, N. E. K. (2018a). Pengembangan Instrumen Penilaian Literasi Kelauan untuk Siswa SMA. Jurnal Kiprah, 6(2), 1-7. [Indonesian]

Hindrasti, N. E. K. (2018b). Reorientasi pembelajaran sains berbasis literasi kelautan reorientation of ocean literacy-based science learning. 
BIOEDUKASI: Jurnal Pendidikan Biologi, 11(2), 7984. https://doi.org/10.20961/bioedukasiuns.v11i2.22842. [Indonesian]

Hoffman, M., \& Barstow, D. (2007). Revolutionizing Earth System Science Education for the 21st Century: Report and Recommendations from a 50-State Analysis of Earth Science Education Standards. In TERC Center for Earth and Space Science Education. http://eric.ed.gov/ERICWebPortal/recordDetai 1?accno=ED497331\&amp; nfls=false

Hsu, S. J., \& Roth, R. (1998). An Assessment of Environmental Literacy and analysis of predictors of responsible environmental behavior held by secondary teachers in Hualien county of Taiwan. Environmental Education Research, 4, 229249., 4, 229-249.

Hungerford, H. R., \& Volk, T. L. (1990). Changing learner behavior through environmental education. In Journal of Environmental Education (Vol. 21, Issue 3, pp. 8-21). https:// doi.org/10.1080/00958964.1990.10753743

Kollmuss, A., \& Agyeman, J. (2010). Mind the Gap : Why do people act environmentally, and what are the barriers to pro-environmental behavior? Mind the Gap : why do people act environmentally, and what are the barriers to. 4622. https://doi.org/10.1080/1350462022014540

Lucrezi, S., Milanese, M., Danovaro, R., Cerrano, C., Lucrezi, S., Milanese, M., Danovaro, R., \& Cerrano, C. (2017). " Generation Nemo ": motivations, satisfaction and career goals of marine biology students. Journal of Biological Education, 9266(October), 1-15. https://doi.org/10.1080/00219266.2017.1385509

Markos, A., Boubonari, T., Mogias, A., \& Kevrekidis, T. (2015). Measuring ocean literacy in pre-service teachers: psychometric properties of the Greek version of the Survey of Ocean Literacy and Experience. Environmental Education Research, December, 1-21. https://doi.org/10.1080/13504622.2015.1126807

National Oceanic and Atmospheric Administration. (2006). Ocean Literacy: Essential Principles and Fundamental Concepts.

Payne, D. L., \& Zimmerman, T. D. (2010). The inclusion of environmental education in science teacher education. The Inclusion of Environmental Education in Science Teacher Education, 81-94. https://doi.org/10.1007/978-90-481-9222-9

Pe'er, S., Goldman, D., \& Yavetz, B. (2007). Environmental literacy in teacher training: Attitudes, knowledge, and environmental behavior off beginning students. Journal of Environmental Education, 39(1), 45-59.
https://doi.org/10.3200/JOEE.39.1.45-59

Pearson, E., Mellish, S., Sanders, B., \& Litchfield, C. (2014). Marine wildlife entanglement: Assessing knowledge, attitudes, and relevant behavior in the Australian community. MARINE POLLUTION BULLETIN. https://doi.org/10.1016/j.marpolbul.2014.10.014

Sattler, S., \& Bogner, F. X. (2016). Short- and long-term outreach at the zoo: cognitive learning about marine ecological and conservational issues. 4622(March). https://doi.org/10.1080/13504622.2016.1144173

Strang, B. C., \& Schoedinger, S. (2007). C y b s 1 w b o 1 ? The Journal of Marine Education, 23(1), 7-9.

Tran, L. U., Payne, D. L., \& Whitley, L. (2010). Research on learning and teaching ocean and aquatic sciences. NMEA Special Report 3, March, 22-26.

Tuncer, G., Tekkaya, C., Sungur, S., Cakiroglu, J., Ertepinar, H., \& Kaplowitz, M. (2009). Assessing pre-service teachers' environmental literacy in Turkey as a means to develop teacher education programs. International Journal of Educational Development, 29(4), 426-436. https://doi.org/10.1016/j.ijedudev.2008.10.003

Umuhire, M. L., \& Fang, Q. (2015). Method and application of ocean environmental awareness measurement: Lessons learned from university students of China. MARINE POLLUTION BULLETIN, 1-6. https://doi.org/10.1016/j.marpolbul.2015.07.067

Yaveltz, B., Goldman, D., \& Pe'er, S. (2009). Environmental literacy of pre-service teachers in Israel: A comparison between students at the onset and end of their studies. Environmental Education Research, 15(4), 393-415.

Yeung, S. P. M. (1998). Environmental consciousness among students in senior secondary schools: The case of Hong Kong. Environmental Education Research, 4(3), 251-268. https://doi.org/10.1080/1350462980040302 